\title{
How to support patients who are crying in palliative home care: an interview study from the nurses' perspective
}

\author{
Kerstin Rydé and Katarina Hjelm \\ Department of Social and Welfare Studies, University of Linköping, Sweden
}

\begin{abstract}
Aim: The aim of this study was to explore how nurses can support patients who are crying in a palliative home care context. Background: In palliative care the nurse has a central role in the team whose duty it is to create a sense of security and trust, as well as to give comfort and support the patients. The nurse's responsibility is to identify different needs of the patients for support and develop a relationship with them. Patients may express their pain, anxiety, fear and suffering by crying. No studies have been found which focus on how nurses can support patients who are crying in different ways and crying for different reasons. Methods: A qualitative explorative study was performed. Semi-structured interviews were held with eight nurses aged 32-63 years (Median 40) working in Swedish palliative home care. The data were analysed using Qualitative Content analysis. Findings: It was reported that the nurse should meet and confirm the patient during different types of crying episodes and should also be able to alternate between being close and physically touching the in such close contact with the patients, the nurse can provide emotional support by showing empathy, merely being present and letting the patients cry as much as they want. When the crying finally stops, the nurse can support the person by speaking with them, showing sensitivity, humility and respect for the patient's wishes. A few examples of the patients' need for information or practical support emerged. The nurse can emotionally support the person who is crying by just being present, confirming, showing empathy, offering a chance to talk and showing respect for their individual needs and the different ways they may cry.
\end{abstract}

Key words: crying; home care services; interview; nurses; nursing care; palliative care; qualitative research; social support; terminal care

Received 19 February 2015; revised 3 December 2015; accepted 31 December 2015; first published online 2 March 2016

\section{Introduction}

Crying is a natural way of expressing sorrow, and grief often affects the whole family in situations such as the approach of death and loss of a loved one (Corless, 2001). Suffering from a severe and incurable disease means a traumatic crisis for most people. Human beings can experience their entire life feeling threatened; even their body's actual

Correspondence to: Kerstin Rydé, Department of Social and Welfare Studies, University of Linköping, Campus Norrköping, SE 60174 Norrkoping, SWEDEN. Email: kerstin.ryde@liu.se integrity, well-being and social roles are threatened and changed (Hytten, 2001). In palliative care, mourning has played a central role for obvious reasons and grief and suffering are ever-present factors in severe chronic medical conditions. Crying has many dimensions and may be viewed primarily as an expression of grief and loss, as well as a call for attention and a way of communicating both anger and joy (Frijda, 1986). There are few studies on this subject of crying in palliative care (Rydé et al., 2007; 2008) although there is a need for emotional support in situations of severe loss and death (Skilbeck and Payne, 2003). There is also a need to provide 
information and practical help to patients and their friends and relatives. The nurse's responsibility in palliative care is to make day-to-day life easier, support and comfort patients and their families in situations when they are crying. The question is how the nurse can best do this, and this question has not previously been studied.

\section{Background}

The definition of palliative care is 'an approach that improves the quality of life of patients and their families facing the problems associated with lifethreatening illness, through the prevention and relief of suffering by means of early identification, impeccable assessment and treatment of pain and other problems, physical, psychosocial and spiritual' (World Health Organization (WHO), 2002: 83). In Sweden dying patients are usually cared for at home if they so wish. In the area under study, which includes multi-professional teams working for the County Council and providing specialised home care $24 \mathrm{~h}$ a day for patients with chronic diseases where the most common reason for palliative care is a cancer diagnosis. In this study the multiprofessional teams were organised by hospitals or primary care (Socialstyrelsen, 2013). In palliative care, the role of the nurse in the team is to bring a sense of security and confidence by providing comfort and creating good relationships with patients and families (Mok and Chiu, 2004). Johnston and Smith (2006) argue that a good relationship is the basis for being able to provide comfort and support to the patient by showing kindness, compassion, respect for the person's independence and integrity and by having good social skills. This makes the ability to identify individual needs for various forms of support - in a situation where the person is crying - very important for the development of high quality nursing, ie, in this case, the relationship between the nurse and the patient (Meleis, 2011).

Crying is natural human behaviour and a common phenomenon (Vingerhoets and Cornelius, 2001). The positive effects of crying can be seen as a way of expressing emotions, communicated through tears and also as a way of understanding their feelings and suffering (Miceli and Castelfranchi, 2003). Men felt that tears had a more negative role to play in social settings than women according to Fischer et al. (2013). Women cry more often in depression,

Primary Health Care Research \& Development 2016; 17: 479-488 while men show more aggression and irritability (Romans and Clarkson, 2008). A study has also shown differences in experiences of shame caused by crying depending on how common crying is and how others in the environment regard shame associated with crying (Becht and Vingerhoets, 2002).

Previous studies have shown that different types of crying constitute a force that creates a sense of emotional balance in cancer patients in palliative care (Rydé et al., 2007) and the same studies have shown that when relatives weep, it is a way of expressing their suffering as well as giving them renewed energy to move forward (Rydé et al., 2008). Others perceive crying as a model, ie, crying that heals, and it has even been developed into a holistic therapy that can be used by health professionals (Griffith et al., 2011). Crying has also been described as having a spiritual healing effect and it also may release toxic substances into the body that temporarily alleviate suffering (Fooladi, 2005). In demanding situations such as in palliative home care, nurses meet individuals who are crying and who may need various kinds of support.

The need for social support varies depending on age, gender, culture and access to - as well as the actual demand for support (Norbeck, 1981). Social support has been defined as an intentional human interaction that involves one or more of the following elements (a) affect, which refers to appreciation, admiration, respect or love, as well as creating a sense of security, (b) affirmation, which includes reinforcement, feedback, and influencing the individual's way of making decisions, and (c) aid, such as objects or money, and spending time in order to help someone (Kahn, 1979). Others have described support in a similar way, ie, emotional support (close relationships), informational support (people who can provide advice, guidance and information) and material support (various types of practical help) (Hanson, 1988). In nursing, it becomes important for the nurse to identify the various aspects of support (Ellis et al., 2005). No studies have been found that describe how a nurse can support crying patients in different situations, and in palliative home care.

\section{Aims}

The aim of this study was to explore how nurses can support patients who cry in a palliative home care context. 


\section{Methods}

\section{Design}

A qualitative explorative study was performed. Semi-structured interviews for data collection were chosen in order to give the participants the opportunity and freedom to express their individual views and thereby reach a deeper understanding of the subject under study (Patton, 2002).

\section{Participants and setting}

The respondents to the study were chosen through purposeful sampling and information-rich cases were recruited (Patton, 2002). To be included in the study, the respondents needed to have worked as nurses for at least one year and have at least one year of experience in palliative home care in Sweden. Eight female nurses participated aged from 32 to 63 years (Median 40) with between eight and 38 years (Median 14) of professional experience and between four and 27 years (Median 9) experience in palliative home care. The study was conducted in specialised palliative care units organised either in hospitals or primary care. Multi-professional home care teams include specialist physicians, nurses, paramedical staff and social workers. The teams care for patients round the clock seven days a week (Socialstyrelsen, 2013).

Three senior managers were contacted in hospital-based palliative care and home care connected with primary health care in one County Council area and they were given verbal/written information. They then first gave verbal and then written permission for the study. The senior manager sent invitations to appropriate respondents by providing written information and by sending an email asking if they were interested in participating in the study. The interviewers received the contact details of interested respondents from the senior manager by email or verbally. The interviewers then contacted them by email or phone to arrange appointments for the interview sessions. The respondents gave their written informed consent to participate in the study before the interviews took place.

\section{Data collection}

Two students in their penultimate term of the nursing programme conducted the interviews in 2011. The interviews were held in a clinical setting in the respondents' workplaces and began with some information about the purpose and implementation of the study. The interview guide was pilot-tested with one respondent (not included in the study), and the only change made was the sequence of the questions. The interview guide used contained background questions, questions about situations where patients cry, which strategies the nurse used and how support can be given in these situations, and what hinders or facilitates the possibility of providing good support in crying situations. The interview guide was developed based on previous studies (Rydé et al., 2007; 2008). The interviews, which lasted between 15 and $30 \mathrm{~min}$, were tape-recorded and transcribed verbatim. Both interviewers were present during all eight interviews and they led four interviews each.

\section{Data analysis}

The interviews were analysed using Qualitative Content analysis (Patton, 2002) by the first author (a nurse experienced in elderly and palliative care) to describe and detect variations in the material patterns, regularities and differences in the origins of the material collected. The analysis began by reading the transcribed material several times in its entirety to get an idea of the content. Any text contents of importance were colour-marked. Coding was carried out by highlighting text that matched the purpose of the study and then entering the code in the margin. The different codes were then compared, and those that had similar content were grouped together into categories and divided into named subcategories and categories. According to Patton (2002), important information can be analysed by coding, categorising and identifying patterns in the material. To increase the trustworthiness of the findings, the content of the categories was checked by the second author and it resulted in a high level of agreement. Examples from the analysis of data, see Table 1.

\section{Ethical considerations}

The study complies with Swedish legislation concerning the ethics regulation in research involving humans (Svensk författningssamling, 2003: 460) and has been conducted in accordance with established ethical principles for human clinical 
Table 1 Examples from analysis of the data

\begin{tabular}{|c|c|c|c|}
\hline Category & Subcategory & Code & Quotation \\
\hline $\begin{array}{l}\text { Encountering and } \\
\text { confirming people } \\
\text { with different } \\
\text { types of crying }\end{array}$ & $\begin{array}{l}\text { To confirm the } \\
\text { silent and tearless } \\
\text { crying }\end{array}$ & $\begin{array}{l}\text { Be sensitive to the } \\
\text { situation }\end{array}$ & $\begin{array}{l}\text { 'He's very reserved; you can't get any response from } \\
\text { him. The only thing we can do with him is to look } \\
\text { into his eyes and there you see a special kind of } \\
\text { crying, internal crying ... we try to coax him to talk, } \\
\text { to show that we are there, if he would only say what } \\
\text { we can help him with' (A3) }\end{array}$ \\
\hline $\begin{array}{l}\text { Balance between } \\
\text { closeness and } \\
\text { physical contact } \\
\text { during the crying } \\
\text { episodes }\end{array}$ & $\begin{array}{l}\text { Just being here } \\
\text { and now without } \\
\text { any touch }\end{array}$ & $\begin{array}{l}\text { Just being here } \\
\text { and now }\end{array}$ & $\begin{array}{l}\text { 'You can't do much ... but sometimes I have tried to } \\
\text { approach and maybe touch the patient and so on, } \\
\text { but if it still does not work either, it all depends on } \\
\text { how upsetting the situation is. Anyway, if I am not } \\
\text { allowed to touch them so maybe I can sit close to } \\
\text { them so I can gradually get closer. But there's not } \\
\text { much to say in those situations' (F1) }\end{array}$ \\
\hline
\end{tabular}

Table 2 Categories and subcategories which emerged in analysis of the data

\begin{tabular}{ll}
\hline Category & Subcategory \\
\hline $\begin{array}{l}\text { Encountering and confirming people with } \\
\text { different types of crying }\end{array}$ & - Allowing their tears to flow, let them cry undisturbed \\
& - Create a relationship as a basis \\
$\begin{array}{l}\text { Balance between closeness and physical } \\
\text { contact during the crying bouts }\end{array}$ & - To confirm the silent tearless crying \\
$\begin{array}{l}\text { Support through conversation and } \\
\text { communication in situations with }\end{array}$ & - To be here and now without any touch \\
patients crying & - To communicate and be with them while they cry \\
& - To plan so there is enough time available for a conversation
\end{tabular}

research in the guidelines stated in the World Medical Association's Declaration of Helsinki (2008). The interview material was anonymised. Participants were given written information about the study, assured of confidentiality and their right to withdraw. All the data collected were stored in a locked space only accessible to the principal investigator.

\section{Results}

Three main categories emerged in the analysis of the material; encountering and confirming people crying in different ways in palliative home care, the balance between closeness and physical contact during crying episodes and support using conversation and communication in situations with patients crying. Some subcategories also emerged, see Table 2. The main categories have been used as headings of the result. The subcategories are not

Primary Health Care Research \& Development 2016; 17: 479-488 recognisable by specific headings for the main categories but by the content of the text.

\section{Encountering and confirming people with different types of crying}

While meeting a person who is crying due to, eg, anxiety, sadness or pain, the palliative home care nurses described the importance of creating an undisturbed environment and an atmosphere of accommodation. It may entail playing down the crying and describing it as something natural, waiting for the tears to flow, not stopping the person crying, letting them cry, not discouraging their weeping, crying it all out, and getting ready to cry.

Let them cry, there's nothing strange about crying ... and it's not something we interrupt, or try to interrupt in any way so they can cry as long as they need to. Nurse F1 
While the patient is crying, the nurses described that they can bring the person a warm blanket, give them something to drink, encourage them to finish crying but not comfort them or say anything like 'it'll be alright in the end', so that they do not disturb their crying. When the patient's crying starts to ebb away, the nurse can continue to provide support in various ways by showing the person that now, 'I'm here for you, I am listening, and I know how you feel and I understand'. The person who is crying also can express or show, 'I've finished now', 'Now I want to talk about something else' because the crying in itself has created a kind of calm and peace. The nurses said that by talking, meeting the person a few times, creating a relationship, getting to know them, the person will weep, then 'the dam gates open and they let their emotions out'. Sometimes there may be time to ask difficult questions but only when a relationship has been built up with them.

Sometimes it's the right time to ask them questions and be a bit annoying when you feel that now I have to broach the subject and sometimes it just isn't the right time. Nurse A1

According to the nurses, crying may also take the form of an internal, tearless weeping which can be harder to perceive: the patients try to suppress their tears, their eyes become watery but no tears are visible. They do not want to show their tears: they keep their crying inside, and avoid talking about difficult things; there are no tears left, and some have other ways of coping with the situation than crying. While supporting the person in a home care setting, the nurse can still confirm what she sees by commenting that she can see the patient is sad, and put words to it, showing that she has noticed the signals, trying to coax them to express what is troubling them.

He's very reserved; you can't get any response from him. The only thing we can do with him is to look into his eyes and there you see a special kind of crying, internal crying ... we try to coax him to talk, to show that we are there, if he would only say what we can help him with. Nurse A3

The patients who do not cry may need the nurse's support by her respecting that they do not want to cry, or that they do not see crying as a way of coping with the situation. The nurses perceived that some people do not feel better by crying but sometimes it can be important to try to encourage them to cry and try to find ways to reach out to the person to be able to help them.

And some people, they don't want to cry in front of us, it's not natural for them, they don't feel better from crying/.../I felt that he didn't want to cry, and then I decided to back off and not confront him when I saw that there was still something there. I felt that he didn't feel comfortable crying in front of me, but at that time I had to let him do as he wanted. Nurse A1

The nurses describe a transition between encouraging tears but then in that situation of a person not wanting to cry, they take a step back and respect the person's wishes not to cry. In order to be consistent and professional, the nurses stated that they needed skills in recognition, sensitivity and showing respect, and they had to find a level of approach that matched the patient's wishes and sense of well-being.

\section{Balance between closeness and physical contact during crying episodes}

All the nurses in home care emphasised the fact that closeness and physical contact are important aids in crying situations due to, eg, the person's feelings of loneliness, fear and/or depression. For example, holding the person's hand tightly, or just lightly, holding them, touching them, hugging and massaging them can be helpful. Support while the person is crying is very much about offering company and physical closeness rather than communication. The nurses also said that physical contact is not always appropriate. So the nurses would assess whether closeness was appropriate in a specific situation because being too close could also undermine the relationship with the person. When physical contact was not suitable, the nurse could offer closeness without any actual touch, or by trying to slowly get close to them. The gradual approach could be described, for example, as asking how they want things to be, waiting until they had calmed down, starting very slowly to approach them and then a little more, starting slowly and then just putting a hand on the patient's 
arm and sometimes crying together with the patient. The nurses described how they needed to be professional in approaching a person in a way that did not compromise the relationship. Sometimes closeness and physical contact were needed where the nurse was encouraging the person to breathe along with the nurse to get them to breathe more slowly to make them feel calmer.

There are emotions that are tremendously important here so it's hard to get her to calm down, to try to change the situation, I think that this can be done partly by holding her, keeping hold of her, perhaps by holding her hand tightly, massaging her so that she can feel my physical contact and encouraging her to breathe along with me. Nurse N1

Some people do not like physical touch and so just being close without touching could sometimes be more appropriate in crying situations. According to the nurses, sometimes closeness could be about just sitting next to the patient, not too close but sometimes very close. The nurse could also make their presence felt through eye contact but sometimes eye contact might also feel inappropriate. In such situations the nurse described how she just sat with the person and did not touch or make any eye contact with them.

You can't do much ... but sometimes I have tried to approach and maybe touch the patient and so on, but if it still does not work either, it all depends on how upsetting the situation is. Anyway, if I am not allowed to touch them so maybe I can sit close to them so I can gradually get closer. But there's not much to say in those situations. Nurse F1

How to deal with physical touch and closeness in home care to be able to provide good support was regarded as a necessity for the nurses. They considered the best method was to sense the atmosphere, wait, listen and just stay there, taking all the time needed and respecting the patient's wishes.

\section{Support using conversation and communication in situations with patients crying}

The nurses said that first of all patients needed to finish crying, they need to calm down and then they can talk. Patients cannot communicate very

Primary Health Care Research \& Development 2016; 17: 479-488 much while they are crying, so the weeping process should be left to run its natural course. However, there are situations when communication can work even while they are crying. When their crying started to stop, the nurses perceived they could support them by asking about their grief and their feelings, asking open-ended questions, offering to call them later but also respecting their wish not to talk.

You can see from the look they give you, you can see that there is an enormous sadness. You can ask an open question to confirm their feelings, and say that it's normal to feel like this. This is to get confirmation that this is normal, because you won't know if you don't ask. Nurse F3

Sometimes there can also be hysterical intense crying and from the nurses' point of view this needs to be interrupted with clear direct communication by saying, 'We can help you'. The hysterical tears risk harming the person rather than helping them because a person who is crying, does not listen and so cannot receive the help that the nurse has to offer.

When it comes to intense crying maybe you have to be a little more direct as I said, to put a stop to it, by saying, 'Listen to me! You need to do what I say! We can help you! Nurse N1

The surroundings for a dialogue/questions also need to be congenial. A separate room can be a more appropriate place to start a dialogue and it may feel embarrassing to cry with other people around; and so asking questions needs to be done in privacy. The conversation may sometimes need to take place without relatives being there, so the patient is able to cry. Relatives want to show they are strong, be protective, but the patient may be scared and so they put on a brave face when other people are around. Weeping together with relatives needs to be encouraged because it can sometimes be a relief for everyone present. It can feel good and create a sense of togetherness, according to the nurses.

Sometimes you see that they want to cry but they don't ... if they are scared or want to look strong because they think that they have to be strong for each other (spouses), I talk to 
them sometimes, to say it's better for you to show your feelings to each other and then allow yourself to go through the grief ... you can see that they clench their teeth, look away and heave a deep sigh. No, now I'm going to be strong for his sake. Nurse A1

The nurses in palliative home care communicate with patients with great sensitivity, humility, warmth and professionalism. Their words are carefully chosen, ie, appropriate to the situation and with great respect in order not to hurt the patient's feelings or give them false hope. It is not the time for consolation, or saying that, 'It'll all work out in the end' or asking insensitive questions like, 'Why are you so upset?' It may be important not to say much, but mostly just be there for them.

There are no words of comfort, but really we just have to be there for them and be on hand if there is anything we can help with/.../but it's more about just being human and warm. Nurse A2

The individual nurse's personal experience of grief and loss can become a source of security that provides strength and facilitates communication with the person who is crying. Knowing how it is to sit there by oneself, being able to understand the other person's situation and knowing how to react, enhances the staff's ability to provide good support while talking to the patient.

And it is important that you have reflected over your own life, to see how you have dealt with the difficult types of weeping or whatever you say, or sadness, handling grief, in whatever way. Because it is very important how you would react in such a situation yourself. Nurse A3

By the nurses planning their time, being able to turn off distractions such as phones and disconnect their own feelings of stress, and by showing the patients that they have time for them, it may be possible to provide support to the person who is crying. There is little point in starting a conversation if you are short of time. In such circumstances the nurses felt they had to be frank with the patient and make an appointment to talk later on.

Closeness and silence then and really show that I'm there for the patient with my body language and everything else. I need to show

I have plenty of time. Nurse A1

To be here and now, to be accommodating, to show that I want to be here and stay with the crying person, is described by the nurses as essential. Over time the nurses in palliative home care have become increasingly aware that 'just' their mere presence is very important for the person who is crying.

\section{Discussion}

This study is unique because it describes the nurses' encounters with people crying in a palliative home care unit organised either by hospitals or primary care and it focuses on how they may best offer support. Every encounter with people who are crying should be seen as unique and individualised care should be provided. The results of this study show that physical closeness and touch are important but should be used with great sensitivity. The nurses' ability to strike a balance between closeness and physical contact is essential for good support. The ability to be sensitive and responsive may be crucial in situations where patients are crying. Physical closeness may undermine the relationship when the person does not want it or feels uncomfortable in the situation. Switching between closeness and distance to the person in palliative care is an important part of the nurses' professional role. The findings demonstrate that the need of support is mainly related to the previously described need for affect and affirmation (Norbeck, 1981) or in other words emotional support (Hanson, 1988). There were limited examples in this study of the need for aid (Norbeck, 1981) either in terms of information or practical support (Hanson, 1988). This could be related to the actual situation when the patient is in palliative care and thus the more practical and informational support may have already been addressed. In this case the nurse can now encounter and confirm the person, and strike a balance between closeness and distance and communicate with the person. Suffering is a central aspect of palliative care, and pain often triggers crying or tearless crying. The nurses' responsibility is to relieve suffering and this can be achieved by supporting people who are crying and they may

Primary Health Care Research \& Development 2016; 17: 479-488 
then regain their emotional balance. A previous study has revealed that patients crying in palliative home care need to be supported in many different ways (Rydé et al., 2007), and particularly need affect, and affirmation (Norbeck, 1981) or/and social support (Hanson, 1988).

The results show that the nurse's mere presence, 'just' being there, can be a support for people who are crying. It is important to consider that the results of this study are from the nurse's perspective and no patients were interviewed. A previous study, focusing on nurses' reflections, has shown that having the courage to be present and confirming, spending time and not trying to 'solve' every existential problem were the most important factors in conversations with patients close to death (Strang et al., 2014a). The results show that the nurse's ability to create an accommodating atmosphere, a stable relationship and peaceful surroundings for the patient is crucial for the patient to be able to cry or not. The nurse has a central role to play in the teamwork around the patient in palliative care and according to $\mathrm{WHO}$ (2002), the purpose of the care is primarily to relieve suffering and improve quality of life. Meleis (2011) argues that the relationship between patient and nurse is at the core of nursing and identifying the individual needs of support is of central importance. The support can have an emotional impact, which means building close relationships, according to Hanson (1988). The relationship between the nurse and the patient is a prerequisite for being able to identify the patient's needs and provide emotional support (Mok and Chiu, 2004; Johnston and Smith, 2006). In a good relationship, the nurse can confirm tears but also support non-weeping, ie, tearless crying. This confirmation may happen in many different ways depending on the situation and the form of weeping.

The nurse may comment that she sees the patient is crying or is on the verge of tears. Physical touch, massage, or just putting a hand on their arm may suffice, depending on the situation. In this way, the need for support can be identified in situations with different types of crying, eg, with or without tears, peacefully and quietly or more intensely.

The results of this study show that independence and respect in crying situations are the crux of good nursing care as previously pointed out (Johnston and Smith, 2006). Also it has been found that tearless crying is important to accept and respect (Rydé et al., 2007). Tearless crying may be the right thing for certain individuals because the tears themselves may not have the positive effects of providing relief, or creating a feeling of balance; and internalised tearless crying may have the same effect. The nurses need a professional approach, to assess the situation and see each individual as unique (Meleis, 2011). The previous study, also conducted in home care, shows furthermore that professionals need to understand the different levels of crying. In some situations comforting the patient may not be the best solution, as some may need privacy (Rydé et al., 2007). There are situations when the nurse should help and support the person not to cry. Crying per se may seem inappropriate and not be a positive experience for the person but crying may create a sense of vulnerability and embarrassment instead.

The person who is crying needs acceptance and a tolerant environment in that situation which can then give them a sense of relief and greater understanding of their feelings and their suffering (Vingerhoets and Cornelius, 2001; Miceli and Castelfranchi, 2003.

The nurses in this study work in a way that makes it possible to focus on encountering patients in situations where they are crying (Socialstyrelsen, 2013). The timeframes that are available can also provide larger spaces for personal interaction than, eg, in a ward with a focus on emergency care where palliative care patients are also tended. The patients in this study are in a later palliative phase. An encounter with a weeping person places great demands on nurses' professionalism. During their training student nurses may feel unprepared and scared to encounter patients in palliative care. By using reflection, training in simulations and drama, their fears of meeting patients in the final stages of life often recede. So this increases their capacity to provide support and they will become more confident when handling crying situations in their future profession as nurses (Strang et al., 2014b). Simulation exercises with patients in the final stages of life during nursing training were found to provide greater knowledge, more self-confidence and a feeling of being more capable to communicate in these situations (Fluharty et al., 2012). Nurses' professional attitudes should be continuously developed through supervision, knowledge sharing, reflection and skills development in the area. 


\section{Trustworthiness}

The trustworthiness of the results was augmented by using an inductive approach and a theoretical framework, theoretical triangulation (Patton, 2002). The sample consists of a homogeneous group of nurses who have significant life experience, extensive professional experience and skills. The nurses in this study may well be regarded as having expertise in palliative care that can only be acquired through many years' experience of clinical work. According to Benner (1982) nurses with this level of knowledge and experience can immediately appraise and solve any problems that may arise and do not waste time on inappropriate solutions.

The interviews were conducted by students who later successfully completed their final year of nursing training, and the content of the interviews was rich and homogenous despite a relatively limited number of interviews. The students freely chose to conduct the study because they were particularly interested in the subject area, and they were not biased by any past experiences in this regard. The analysis showed that the same content is repeated and thus it provides a homogenous picture, which also enhances the trustworthiness (Patton, 2002). The study design was chosen to illustrate and try to understand the respondents' different perspectives of support and crying situations, and not to generalise findings. However, the findings collected and analysed from the study data can be transferred to groups and contexts with similar characteristics.

\section{Conclusion}

The nurse can emotionally support the person who is crying by being present, affirmative, offering empathy, offering a chance to talk and showing respect for the individual's needs regardless of their type of crying, with or without tears. The different forms of social support needed affect and affirmation or in other words emotional support.

\section{Acknowledgements}

The authors thank the students Marija Naumova and Frida Svensson who conducted the interviews and the nurses who participated in the interviews.

\section{Conflicts of Interest}

None.

\section{References}

Becht, M. and Vingerhoets, A. 2002: Crying and mood change: a cross-cultural study. Cognition and Emotion 16, 87-101.

Benner, P. 1982: From novice to expert. The American Journal of Nursing 82, 402-7.

Corless, I. 2001: Bereavement. In Rolling-Ferrell, B. and Coyle, N., editors Textbook of palliative nursing. New York: Oxford University Press, 353-62.

Ellis, D., Jackson, D. and Stevenson, C. 2005: A concept analysis of nursing support. In Cutcliffe, J. and McKenna, H., editors The essential concepts of nursing: building blocks for practice. New York: Elsevier, 273-85.

Fischer, A., Eagly, A. and Oosterwijk, S. 2013: The meaning of tears: which sex seems emotional depends on the social context. European Journal of Social Psychology 43, 505-15.

Fluharty, L., Sorell-Hayes, A., Milgrom, L., Malarney, K., Smith, D., Reklau, M.A., Jeffries, P. and McNelis, A.M. 2012: A multi-site, multi-academic track evaluation of endof-life simulation for nursing education. Clinical Simulation in Nursing 8, e135-143.

Frijda, N. 1986: The emotions. New York: Cambridge University Press.

Fooladi, M. 2005: The healing effects of crying. Holistic Nursing Practice 19, 248-55.

Griffith, M.B., Hall, J. and Fields, B. 2011: Crying that heals. Journal of Holistic Nursing 29, 167-79.

Hanson, B.S. 1988: Social network, social support and health in elderly men. A population study. Dissertation, Lund University.

Hytten, K. 2001: Att bemästra svår sjukdom. In Kaasa, S., editor Palliativ behandling och vård (Master severe illness In palliative treatment and care. Lund: Studentlitteratur, 21-29.

Johnston, B. and Smith, L.N. 2006: Nurses' and patients' perceptions of expert palliative nursing care. Journal of Advanced Nursing 54, 700-9.

Kahn, R.L. 1979: Ageing and social support. In Riley, M.W., editor Ageing from birth to death interdisciplinary perspectives. Colorado: Westview Press, Boulder, 77-91.

Miceli, M. and Castelfranchi, C. 2003: Crying: discussing its basic reasons and uses. New Ideas in Psychology 21, 247-73.

Meleis, A.I. 2011: Theoretical nursing: development and progress, fifth edition. Philadelphia: Wolters Kluwer Health/Lippincott Williams \& Wilkins.

Mok, E. and Chiu, P. 2004: Nurse-patient relationships in palliative care. Journal of Advanced Care 48, 475-83.

Norbeck, J. 1981: Social support: a model for clinical research and applications. Advanced Nursing Science 3, 43-59. 
Patton, M.Q. 2002: Qualitative research \& evaluation methods, third edition. London: SAGE Publications.

Romans, S. and Clarkson, R. 2008: Crying as a gender indicator of depression. Journal of Nervous \& Mental Disease 196, 237-43.

Rydé, K., Friedrichsen, M. and Strang, P. 2007: Crying: a force to balance emotions among cancer patients in palliative home care. Palliative and Supportive Care 5, 51-59.

Rydé, K., Strang, P. and Friedrichsen, M. 2008: Crying in solitude or with someone for support and consolation - experiences from family members in palliative home care. Cancer Nursing $5,345-53$.

Svensk författningssamling, SFS. 2003: 460: Lag om etikprövning som gäller människor (Swedish Code of Statutes. Law on the ethical review of research on humans). Retrieved 1 December 2014 from http://www.riksdagen.se/sv/DokumentLagar/Lagar/Svenskforfattningssamling/Lag-2003460-ometikprovning_sfs-2003-460/?bet=2003:460.

Skilbeck, J. and Payne, S. 2003: Emotional support and the role of clinical nurse specialists in palliative care. Journal of Advanced Nursing 43, 521-30.

Socialstyrelsen. 2013: Nationellt kunskapsstöd för god palliativ vård i livets slutskede (National Board and Health and Welfare-National knowledge support for good palliative end of life care). Retrieved 15 January 2015 from http:// www.socialstyrelsen.se/Lists/Artikelkatalog/Attachments/ 19107/2013-6-4.pdf.

Strang, S., Henoch, I., Danielson, E., Browall, E. and Melin-Johansson, C. 2014a: Communication about existential issues with patients close to death-nurses' reflections on content, process and meaning. Psycho-Oncology 23, 562-68.

Strang, S., Bergh, I., Ek, K., Hammarlund, K., Prahl, C., Westin, L., Österlind, J. and Henoch, I. 2014b: Swedish nursing students' reasoning about emotionally demanding issues in caring for dying patients. International Journal of Palliative Nursing 20, 194-200.

Vingerhoets, A.J. and Cornelius, R.R. (editors) 2001: Adult crying: a biopsychosocial approach. Philadelphia, PA: Brunner/Routledge.

World Medical Association Declaration of Helsinki. 2008: Ethical Principles for Medical Research Involving Human Subjects. Retrieved 1 December 2014 from http://www. wma.net/en/30publications/10policies/b3/.

World Health Organization (WHO). 2002: Definition of Palliative Care. National cancer control programs: policies and managerial guidelines. Geneva: WHO, 83 pp. Retrieved 1 December 2014 from www.who.int/cancer/publications/ nccp2002/en/. 